\title{
Nasilje in družbena (ne)pravičnost Intervju z Vittoriom Bufacchijem
}

Mitja Sardoč

ittorio Bufacchi je višji predavatelj na Oddelku za filozofijo na Univerzi Cork na Irskem. Diplomiral je na Univerzi v Sussexu, magistriral (1989) in doktoriral (1994) pa na londonski School of Economics. V svoji doktorski disertaciji pod mentorstvom profesorja Briana Barryja se je ukvarjal s tradicijo družbenih pogodb v sodobni politični filozofiji. Poučeval je na Univerzi v Manchestru, Univerzi Yale in Univerzi v Dublinu ter bil gostujoči predavatelj na Univerzi v Koloradu v Boulderju, Kolidžu Dartmouth in na Univerzi LUISS Guido Carli v Rimu.

Je avtor del Social Injustice: Essays in Political Philosophy (Palgrave, 2012) in Violence and Social Justice (Palgrave, 2007), urednik zbornikov Violence: A Philosophical Anthology (Palgrave, 2009) in Rethinking Violence (Routledge, 20II) ter gostujoči urednik posebne številke revije Revue Internationale de Philosophie $\mathrm{z}$ naslovom Philosophy and Violence (let. 67, št. 3, 2013). Je tudi soavtor (skupaj s Simonom Burgessom) dela Italy Since 1989 (Palgrave, 1998) in sourednik (skupaj z Richardom Bellamyjem in Dariem Castiglionejem) dela Democracy and Constitutional Culture in the Union of Europe (Lothian, 1995). Med drugim je pisal za Guardian, Irish Times, Irish Examiner in RTÉ Brainstorm.

Njegova glavna področja raziskovanja so družbena nepravičnost, človekove pravice, nasilje in rimska politična misel. Trenutno dela na dveh knjižnih projektih: o Ciceronu in o filozofskih temeljih človekovih pravic. Živi v Corku na Irskem z ženo Jools Gilson in dvema otrokoma. www. vittoriobufacchi.com 
Kot pišete v predgovoru k svoji knjigi Violence and Social Justice, sta »najbolj pereća problema $v$ sodobni politični filozofiji nepravičnost in nasilje«. Ali je bil pri našem razumevanju nepravičnosti in nasilja [in njunega presečišča] $v$ zadnjih nekaj desetletjih dosežen kakšen napredek?

Mislim, da smo na področju nasilja dosegli nekaj napredka, manj na področju družbene nepravičnosti in skoraj nič na presečišču nasilja in nepravičnosti. Napredek, ki smo ga dosegli na področju razumevanja nasilja, je vse večje zavedanje, da je nasilje več kot le droben kriminal ali odklonsko vedenje posameznikov. Največji povzročitelj nasilja na svetu ni posameznik, ki se vede neprimerno, temveč sodobna država. Državno nasilje je lahko neposredno ali posredno. Neposredno državno nasilje se pojavlja $\mathrm{v}$ različnih oblikah, na primer $\mathrm{v}$ obliki represivnih pravnih ureditev, kot je bil denimo apartheid v Južni Afriki oziroma je smrtna kazen ali nedavna prepoved splava $v$ ameriški zvezni državi Alabama, ki je splav prepovedala tudi v primeru posilstva ali incesta, zaradi česar je splav postal kaznivo dejanje, za katerega je zagrožena kazen do 99 let zapora oziroma dosmrtna zaporna kazen. Druge oblike neposrednega državnega nasilja vključujejo državni terorizem, bodisi proti tujim državljanom bodisi proti domačim, in seveda vojne.

O posrednem državnem nasilju govorimo takrat, ko država ne ukrepa in dopušča, da se zgodijo stvari, ki bi jih morala preprečiti. Primeri posrednega nasilja vključujejo nepripravljenost ameriških oblasti, da bi sprejele ustrezno zakonodajo o nadzoru orožja, kljub številnim strelskim incidentom in pokolom $\mathrm{v}$ šolah ( $\mathrm{k}$ temu vprašanju se bom vrnil pozneje), ter številne primere nekaznovanja, ko se država odloči, da ne bo preiskovala določenih kaznivih dejanj, in tako de facto omogoča nekaznovanje. Na primer, marsikje po svetu kljub visoki stopnji nasilja v družini ali nasilja na podlagi spola to pogosto ostaja nekaznovano, ker se država odloči, da ne bo izvajala že obstoječih zakonov, s čimer nasilje še naprej omogoča. Statistični podatki izpred nekaj let kažejo, da ima Gvatemala eno najvišjih stopenj umorov žensk na svetu, UNICEF pa je leta 20 II poročal, da sta vsak dan v povprečju ubiti dve ženski. Toda vsaj zavedanje, da je nekaznovanost, ki jo omogoča država, nesprejemljiva, je vse večje. Organizacije in aktivisti za človekove pravice so $\mathrm{v}$ zadnjih nekaj desetletjih opravili izjemno delo na področju ozaveščanja - pri tem ne smemo pozabiti na veliko tveganje, ki so mu izpostavljeni -, da bi nas opomnili, da je nasilje vedno politično, kar kaže na določen napredek pri našem razmišljanju o nasilju.

Kar se tiče družbene nepravičnosti, menim, da smo na tem področju dosegli manjši napredek. Pred nekaj leti se je ponovno pojavilo zanimanje 
za družbeno nepravičnost kot pojem, ki je neodvisen oziroma ni v celoti odvisen od teorije družbene pravičnosti. S tem mislim na delo The Faces of Injustice (1990) Judith Shklar in Justice and the Politics of Difference (1990) Iris Marion Young pa tudi na znano debato med Nancy Fraser in Axlom Honnethom o identiteti, prepoznavanju in redistribuciji. Vendar se zdi, da sodobne politične filozofije splošna teorija družbene nepravičnosti ne zanima, temveč se o njej vedno razpravlja samo $v$ povezavi z določenimi vprašanji, na primer v zvezi z zgodovinsko krivico, priseljevanjem ali svetovno revščino. Po mojem mnenju je značilnosti družbene nepravičnosti treba razumeti, preden oblikujemo načela družbene pravičnosti. Ali z drugimi besedami: družbena pravičnost je rešitev problema, problem pa je družbena nepravičnost. Problem bi morali razumeti, preden ponudimo rešitev, in prav zaradi tega potrebujemo splošno teorijo družbene nepravičnosti, vendar se zdi, da se je napredek na tem področju vsaj za zdaj ustavil.

Na presečišču nasilja in družbene nepravičnosti je treba še veliko postoriti. Problem na tem področju lahko ponazorimo s primerom. V zadnjih nekaj letih se je pojavilo veliko literature o etiki kolonializma oziroma o tem, kaj je $s$ kolonializmom narobe. $\mathrm{K}$ tej pomembni razpravi so prispevali številni izjemni avtorji, med njimi Lea Ypi, Margaret Moore in Laura Valentini. Vse navajajo močne argumente za napake kolonializma, hkrati pa zanemarjajo njegovo nasilje, in sicer tako, da ga jemljejo za samoumevno in napake kolonializma iščejo drugje. Menim, da je to zavajajoče, saj je za razumevanje nepravičnosti kolonializma potrebno pravilno razumevanje nasilja, kot trdim v svojem članku, Colonialism, Injustice, and Arbitrariness'v reviji Journal of Social Philosophy (2017).

\section{Obširno ste pisali o vprašanjih, povezanih združbeno (ne)pravič- nostjo. Kako to, da ste se začeli zanimati za nasilje? Kaj je spod- budilo vaše zanimanje za to področje znanstvenih raziskav?}

$S$ tem, kako sem se začel zanimati za nasilje, je povezana zanimiva zgodba. Nekega torkovega jutra septembra 20or sem v svoji pisarni pripravljal predavanja za predmet, ki naj bi ga začel predavati konec septembra. Predmet se je imenoval »Uvod v politično filozofijo «, učni načrt pa je bil sestavljen iz dokaj običajnega nabora ključnih akterjev iz zgodovine politične misli (Hobbes, Locke, J. S. Mill, Marx) in ključnih pojmov politične filozofije (demokracija, enakost, družbena pravičnost, izkoriščanje, patriarhalnost). Nenadoma pa je na vrata potrkala kolegica Dolores Dooley in mi rekla: »Tole moraš videti, pridi hitro v sosednji pub.« Leta 200 I nismo imeli mobilnih telefonov in na oddelku nismo imeli televizije, zato je 
strateški »umik v sosednji pub« pomenil novice v živo. Nemudoma sem prenehal z delom in šel do sosednjega puba. Tam je že bila zbrana velika množica in vsi so v popolni tišini zrli v televizijski ekran. Bil je II. september 20oı. Opazovali smo potek najhujšega terorističnega grozodejstva $\mathrm{v}$ sodobni zgodovini.

Tistega dne se spominjam takole: ko sem stal $\mathrm{v}$ irskem pubu in gledal posnetke zrušenja Svetovnega trgovinskega centra v New Yorku, nisem mogel dojeti, kaj gledam. Bilo je, kot da moji možgani niso hoteli obdelati groze, ki so jo prikazovali v živo na televiziji. Spominjam se, da sem se skušal prepričati, da so vsi zapustili stavbo, preden je letalo trčilo vanjo, in da bodo zagotovo vsi preživeli. Hkrati pa sem vedel, da se bo po tem dnevu spremenilo vse.

$\mathrm{V}$ pubu nisem ostal dolgo; enostavno nisem mogel gledati prenosa teh dogodkov v živo. Namesto tega sem se vrnil v pisarno, v udobje svojih knjig in varnost svojih mislih. $\mathrm{V}$ tistem trenutku, ko sem zagledal gradivo za svoja predavanja, sem se odločil, da zavržem vse, kar sem nameraval učiti v novem semestru. Ko sem dva tedna pozneje spoznal novo generacijo študentov, sem jim rekel, da bomo kljub temu, da se vpisali predmet »Uvod v politično filozofijo «, delali nekaj povsem drugega od prvotno opisanega. Povedal sem jim, da so dogodki iı. septembra tako resni, tako zapleteni in tako pomembni, da preprosto moramo poskušati razumeti dogodke tega dneva, ki je spremenil zgodovino. Povedal sem jim tudi, da smo dolžni poskušati razumeti dogodke ir. septembra in da bo neprijetno, ampak da je univerza pravi kraj za razmišljanje o političnem nasilju na ravni posameznika in družbe.

Če pogledam nazaj, vsebina predmeta, ki sem jo pripravil, ni bila zelo koherentna, bila je mešanica literature o različnih temah, vključno $s$ terorizmom, teorijo pravične vojne, revolucijo, državljansko nepokorščino, mučenjem in strukturnim nasiljem. Ampak mislim, da je bila na nek način smiselna. Jeseni 2001 so bila naša čustva $\mathrm{v}$ zvezi $s$ političnem nasiljem zelo surova, zato smo vsi čutili potrebo po temeljitem premisleku na kolektivni ravni. Imel sem tudi veliko srečo, da si je ravno tisto leto moj predmet izbralo veliko gostujočih študentov iz ZDA. Razprave, ki sem jih takrat imel s študenti, niso bile vedno lahke ali pomirjujoče, toda bile so iskrene in nujne.

Ko sem iskal knjige in članke, ki bi jih lahko ponudil študentom $\mathrm{v}$ branje, sem ugotovil, da je bilo, kljub siceršnji zelo obsežni literaturi o številnih vidikih nasilja, na področju filozofije s strani filozofov na to temo napisanega zelo malo. Zaradi tega sem se odločil napisati knjigo Violence and Social Justice (2007). Od leta 2001 skoraj vsako leto poučujem predmet o nasilju. 
Zaradi dogodkov ir. septembra sem se začel zanimati za filozofijo nasilja, vendar moje zanimanje za nasilje ni omejeno na vprašanje terorizma. Pravzaprav se terorizem v moji knjigi komajda pojavlja. Šele pet let po objavi svoje knjige sem objavil članek (skupaj z Jean Mario Arrigo) o problematičnosti hipotetičnega scenarija tiktakajoče bombe in zakaj uporaba mučenja za boj proti terorizmu ni nikoli upravičena: ,Torture, Terrorism and the State: A Refutation of the Ticking-Bomb Argument' v Journal of Applied Philosophy (2006).

Obsežna literatura o nasilju v tako raznolikih disciplinah, kot so psihologija, politologija, kriminologija, sociologija, kulturologija, antropologija, pedagogika in filozofija, je dokaz o kompleksnosti nasilja. Kaj je glavni prispevek filozofije k razpravam o nasilju?

Nasilje je v akademskih krogih vedno vzbujalo veliko pozornosti, in to upravičeno. Ljudje se bodo vedno spraševali, ali je nasilje posameznika neizogibno, ker je del naše človeške narave, neizogibno utelešenje prvinskega nagona, ki ga ni mogoče vedno nadzorovati, in opomnik, da je celo homo sapiens globoko v sebi žival. Poleg tega je nasilje bistvo politike, bodisi zato, ker je bilo nasilje vedno (in je do neke mere še vedno) najbolj zanesljivo orodje osvajanja in prevlade, bodisi zato, ker v demokraciji skušamo preprečiti, da bi konflikti in nesoglasja prerasli v nasilje. O teh vprašanjih bodo še naslednjih nekaj stoletij razmišljali psihologi, antropologi, kriminologi, sociologi, politologi in strokovnjaki za mednarodne odnose.

Filozofija lahko $\mathrm{k}$ tej razpravi prispeva veliko, čeprav tega filozofi in nefilozofi ne priznavajo vedno. Ne pozabimo, da je celo osnovno vprašanje o naši človeški naravi v prvi vrsti filozofsko vprašanje. Filozofija je nujno potrebna, saj nam nudi pojmovna orodja, ki jih uporabljamo za oblikovanje vprašanj o našem obstoju. Na primer, obstaja majhno raziskovalno področje, kjer poskušajo ugotoviti, ali je nasilje vgrajeno v naš DNK. Pri iskanju dokončnega odgovora na to vprašanje se moramo vedno spomniti, da je tudi metodologija znanstvenega raziskovanja vprašanje filozofske razprave. Vsako empirično znanstveno raziskovanje temelji na teoretičnih predpostavkah, zato je filozofija pri njem vedno prisotna, ne glede na to, ali se tega zavedamo ali ne. In enako velja za raziskave nasilja v družboslovju, kriminologiji in vojnih študijah. Raziskovanje nasilja je smiselno le, če vemo, kaj iščemo, in za to potrebujemo definicijo nasilja.

Toda bodimo bolj natančni. Mislim, da filozofija pomembno prispeva $k$ našemu razumevanju nasilja: na pojmovni ravni in na normativni (moralni) ravni. Preden se lahko pogovarjamo o nasilju, moramo ugotoviti pomen tega izraza, in ko gre za zagotavljanje pojmovne jasnosti, je 
filozofija kot disciplina še vedno neprekosljiva. Mogoče sem staromoden, vendar se še vedno strinjam z opisom Johna Locka, ki filozofa označuje kot »delavca nižje vrste«. V Eseju o človeškem razumu (1690) Locke pravi, da je naloga filozofa $\gg$ nekoliko čistiti in odpravljati grobljo, ki leži na poti do spoznanja «. Groblja, ki jo ima v mislih Locke, je pojmovna zmeda in nejasnost, nadaljuje pa pravzaprav $s$ tem, da so sovražnik filozofije $\gg$ nejasne in nepomembne oblike govora ter zloraba jezika «.

Ko sem začel pisati svojo knjigo Violence and Social Justice, sem si zastavil dva cilja: prvič, da podam jasno, natančno opredelitev nasilja, in drugič, da ocenim, če, kdaj in kako je nasilje lahko upravičeno. Takrat sem domneval, da sta ti vprašanji ločeni in da je pojem nasilja mogoče opredeliti v vrednostno nevtralnem jeziku; zdaj sem $\mathrm{v}$ to manj prepričan. Toda kljub vprašanju, ali je mogoče definicijo nasilja ločiti od moralnega vrednotenja nasilja, ostaja dejstvo, da gre za globoko filozofska vprašanja, in še vedno menim, da je od vseh disciplin filozofija najboljša za reševanje teh vprašanj. Da bi se sprijaznili z utemeljitvijo nasilja, potrebujemo ozadje normativne in uporabne etike, morda celo metaetike, ki sta seveda veji filozofije. Mimogrede, o utemeljitvi nasilja obstaja čudovita nova knjiga Elizabeth Frazer in Kimberly Hutchings Can Political Violence Ever Be Justified? (2019). Je zelo kratka, a zelo natančna in spodbudna. Toplo jo priporočam vsem, ki jih zanima to vprašanje.

Medtem ko $z$ »ozko« opredelitvijo nasilja tvegamo, da ne zajamemo različnih oblik nasilja [in nepravičnosti], je problematična tudi »široka« opredelitev, in to kljub temu, da prispeva $k$ večjemu zavedanju $v$ zvezi $z$ nasiljem. Kako bi $\gg$ ocenili« prednosti in slabosti obeh pristopov? Ali obstaja način, kako premagati to oviro?

V svoji knjigi Violence and Social Justice trdim, da razlikujemo med ozkim (OPN) in širokim pojmovanjem nasilja (ŠPN). To razlikovanje izvira iz nerešenega vprašanja $\mathrm{v}$ zvezi z etimologijo besede violence, pri kateri nas latinski izraz viss, kar pomeni sila, moč ali jakost, usmeri v dve različni smeri: violentia, kar pomeni silovitost oziroma strastna in nenadzorovana sila, in violare, kar pomeni kršitev oziroma kršiti. OPN poudarja nasilno dejanje storilca nasilja, ki povzroča škodo ali bolečino, medtem ko ŠPN daje večji poudarek na zlorabo, ki jo je utrpela žrtev ali preživela oseba nasilja. Razlika je komaj zaznavna, toda pomembna.

OPN zajema najbolj očiten in na videz nesporen vidik nasilja, vendar za ceno zanemarjanja drugih pomembnih razsežnosti tega pojava. Nasilje je veliko več kot fizično dejanje, katerega cilj je namerno povzročiti škodo 
ali bolečino drugim. Takšno zelo ozko razumevanje nasilja je problematično, saj zanemarja psihološko nasilje, na primer grožnjo z nasiljem, javno poniževanje, zločin iz sovraštva ali celo zanemarjanje. Obsežna literatura o nasilju v družini nas uči, da nasilje obstaja tudi tam, kjer ni nobenih modric, in to sporočilo se širi zelo počasi. Prav tako OPN predvideva, da bi bilo nasilje treba opredeliti z vidika storilca nasilja, pri čemer je poudarek na razlogih, željah in dejanjih osebe, ki izvaja nasilje. Tudi to je zelo problematično. Razlog, zakaj je nasilje tako velik problem, ne leži v tem, kar nam pove o določenih ljudeh, ki so sposobni narediti neopisljive stvari, ampak zaradi vpliva, ki ga ima na žrtve in preživele. Zato osebno menim, da bi bilo treba nasilje opredeliti z vidika žrtve oziroma preživelega, ne pa storilca

Nekatere od omenjenih težav z OPN je mogoče preseči s ŠPN, zato ga je treba razumeti kot korak v pravo smer. $S$ poudarkom na kršitvi, ki se zgodi, ko pride do nasilja, se pozornost preusmeri s storilca na žrtev oziroma preživelega. Na nasilje zdaj gledamo z drugega zornega kota: pozornost je na tem, da je nekaj ali nekdo oškodovan, da je bila prekoračena določena meja. Težava s ŠPN je, da sicer upravičeno poudarja pojem kršitve, vendar nam mora povedati tudi, kaj točno se krši, ko se nasilje izvaja. Standardni odgovor na to vprašanje je, da je nasilje kršitev pravic. Takšen pristop je privlačen, vendar problematičen. Pojem pravic je zapleten in sporen, zato definicija nasilja kot kršitev pravic omogoča preveč nejasnosti. Poleg tega ne drži vedno, da nasilje vključuje kršitev pravic. V sadomazohizmu nasilje obstaja, ne pa tudi kršitev pravic, če upoštevamo ustrezno privolitev. Enako velja za nekatere športe, na primer boks ali mešane borilne veščine.

Verjamem, da obstaja način, kako premagati to oviro, in sicer na »tretji način «, pri katerem pojem nasilja obravnavam kot kršitev integritete, natančneje, integritete preživelega. Tu moramo biti previdni: ne mislim integritete na način, kot se ta izraz uporablja v etiki kreposti, kjer se nanaša na moralni značaj nekoga, ki ga povezujemo z nepokvarljivostjo in odkritostjo. Namesto tega z integriteto preprosto mislim na nekaj, kar je nedotaknjeno, celovito in nezlomljeno. Potrditev za moje pojmovanje nasilja kot kršitev integritete je mogoče najti v eni najboljših knjig o nasilju, kar sem jih kdaj prebral: Aftermath: Violence and the Remaking of Self (2002) Susan Brison, ki v tej izjemni knjigi analizira vpliv na svoj »jaz«, potem ko je preživela skoraj usoden poskus spolnega nasilja. Jezik, ki ga uporablja, jasno kaže, da nasilja, ki ga je pretrpela, ni mogoče preprosto omejiti na telesno škodo oziroma poškodbe, ki jih je utrpela. Namesto tega je najbolj očitna kršitev njene celovitosti v vseh njenih oblikah. Svojo izkušnjo osebe, ki je preživela nasilje, poskuša razumeti tako, da jaz označi 
za »poškodovan«, doživi »razkol med preteklostjo in sedanjostjo «, kako je bil njen svet »porušen « in »uničen «, kako lahko nasilno dejanje prekine povezavo med jazom in ostalim človeštvom. Na koncu nam avtorica (2002: IIO) pove, da nasilje uničuje jaz: »Uničilo je popolnoma dobro, nedotaknjeno življenje. « Jezik, ki ga uporablja, je natančen in zgovoren: da bi lahko nekaj uničili, mora to najprej obstajati kot nedotaknjeno. Ravno ta pojem, da je nekaj nezlomljeno ali nedotaknjeno, poskuša zajeti pojmovanje nasilja kot kršitve integritete. Pred nastopom nasilja imamo fizično (telesno) in duševno (psihološko) integriteto, nekateri bi rekli, da imamo tudi duhovno integriteto. Menim, da je z nasilnim dejanjem ta integriteta kršena.

Zdaj pa malce bolj »praktično« vprašanje: nasilje je vztrajen problem tudi $v$ šolah (zlasti $v$ ZDA). Odzivi na to težavo so bili različni, na primer $v$ obliki politike »ničelne tolerance«, kar pa je sprožilo številne empirične in pojmovne težave. Kaj so po vašem mnenju najbolj pereči izzivi, bodisi empirični bodisi pojmovni, povezani z nasiljem vizobraževalnih ustanovah?

Nasilje v šolah ima dolgo, zapleteno zgodovino. V i9. stoletju je bilo uvedeno obvezno šolanje, da bi otroke najprej ukrotilo, nato pa jih usposobilo. Šole so takrat predstavljale rešitev za vse večji problem drobnega uličnega kriminala, njihov namen pa je bil, da bi se mali prestopniki izognili življenju na ulici. Šole so bile seveda izjemno nasilne ustanove, kjer so otroke trpinčili in poniževali. Na Irskem je bila telesna kazen v šolah od leta 1982 domnevno prepovedana, vendar je šele leta 1996 postala kaznivo dejanje. Metode telesnega kaznovanja, ki so se uporabljale v irskih šolah, so vključevale usnjen pas, palico, ravnilo, noge pohištva in veje dreves. Zelo podobno je v Veliki Britaniji, kjer je prepoved telesnega kaznovanja v britanskih državnih šolah začela veljati leta 1986 , v zasebnih, plačljivih šolah v Angliji in Walesu šele leta 1998, na Škotskem šele leta 2000, na Severnem Irskem pa šele leta 2003 . Neverjetno je, da je v devetnajstih zveznih državah v ZDA v nekaterih šolah uporaba telesne kazni za discipliniranje otrok še vedno dovoljena.

Toda nasilje, ki smo mu danes priča v šolah, je (večinoma) drugačne vrste in obsega štiri različne oblike: nasilje med učenci, nasilje učencev do učiteljev, nasilje učiteljev do učencev in nasilje tujcev do učencev in otrok zunaj šole. Prva oblika nasilja, in sicer tista med učenci, je bolj kompleksna, kot si morda mislimo. Medtem ko je največ pozornosti deležno fizično nasilje, je psihološko nasilje $\mathrm{v}$ obliki ustrahovanja $\mathrm{v}$ šolah doseglo skoraj epidemične razsežnosti, še posebno od pojava pametnih telefonov 
in številnih družbenih omrežij, ki jih množično uporabljajo najstniki. Naraščajoča stopnja samomorov med učenci pa je le vrh ledene gore.

Nasilje učencev do učiteljev je prav tako v porastu. Po podatkih ameriškega ministrstva za izobraževanje je v ZDA med 201 in 2012 približno $9 \%$ učiteljev poročalo, da so fizično ogroženi, $5 \% \mathrm{pa}$, da so v šoli doživeli fizični napad. Od leta 1997 do 200 i je bilo zoper učitelje storjenih 1,3 milijona kaznivih dejanj (vključno s 473.000 nasilnimi zločini). Nasilno vzdušje $\mathrm{v}$ šolah prispeva $\mathrm{k}$ temu, da se mnogi učitelji odločijo opustiti ta poklic. Iz šol po Veliki Britaniji naj bi po manj kot dveh letih odšel približno vsak peti učitelj (I8\%).

Značilnosti nasilja učiteljev do učencev se od I9. stoletja dalje spreminjajo, vendar ta oblika nasilja ni povsem izginila. $V$ večini civiliziranih držav palice ne uporabljajo več, še vedno pa določene skupine otrok s strani učiteljev namerno ali nenamerno doživljajo nasilje. Zaskrbljujoča je nezmožnost, nesposobnost oziroma nepripravljenost učiteljev na sodelovanje $\mathrm{z}$ učenci $\mathrm{z}$ motnjami $\mathrm{v}$ telesnem, kognitivnem ali duševnem razvoju. Otroke iz etničnih manjšin se pogosto obravnava drugače kot druge otroke. Poleg tega številne šole še vedno nočejo sprejeti učencev iz skupnosti LGBT+.

In za konec: šole so pogosto prizorišče grozljivih nasilnih dejanj. Šolski pokoli so ponavljajoča se tema v mednarodnih novicah in človek se vpraša, ali država stori dovolj za zaščito otrok in učiteljev pred takšnimi katastrofami. Aprila 2018 sem po množičnem streljanju v šoli na Floridi za RTÉ Brainstorm napisal prispevek z naslovom Are School Shootings a Human Rights Issue? V njem zavrnem standardni odziv politike na tovrstne tragedije, ki jih pripisuje »čistemu zlu« in skorumpirani, zli naravi storilcev. Trdim, da je v tem kontekstu vsakršno sklicevanje na zlo nekoristno, celo zavajajoče. Če je nasilje sistematično, ponavljajoče se in stalno, kot so običajno množična streljanja v šolah v ZDA, gre za težavo strukturne narave. Posamezniki niso nedolžni, vendar posameznik lahko deluje samo znotraj sistema. Kadar gre za strukturno nasilje, je odgovornost kolektivna, ne osebna. Namesto da bi opozarjali na zlo znotraj človeka ali na njegove duševne in moralne pomanjkljivosti, je mogoče uporabiti drugačen pristop.

Tretji člen Konvencije o otrokovih pravicah določa, da morajo biti pri upravnih in zakonodajnih organih v prvi vrsti najboljši interesi otroka. 19. člen pravi, da »države pogodbenice sprejmejo vse ustrezne zakonodajne, upravne, socialne in izobraževalne ukrepe za zaščito otroka pred vsemi oblikami fizičnega ali duševnega nasilja, poškodb ali zlorab «. Primarni naslovniki človekovih pravic so vlade po svetu in njihovi izvoljeni politiki, zato neizpolnjevanje specifičnih dolžnosti za imetnike pravic pomeni 
kršitev človekovih pravic. Za izpolnitev svoje dolžnosti imajo zakonodajalci na voljo dve povsem različni strategiji. Ena je namestitev oboroženih varnostnikov $\mathrm{v}$ polni pripravljenosti $\mathrm{v}$ vsako šolo $\mathrm{v}$ Ameriki in morda celo oboroževanje učiteljev. To je, odkrito rečeno, absurdno in bi prostor učenja ter igranja spremenilo v vojaško in potencialno vojno območje. Alternativna strategija je prisluhniti preživelim teh pokolov in storiti najbolj logično stvar $v$ trenutnih okoliščinah: zmanjšati, če že ne odpraviti, dostop do orožja, začenši z avtomatskim orožjem, in vzpostaviti strožja pravila glede tega, kdo lahko kupi potencialno smrtonosno orožje. To bi bilo enostavno, hitro in razmeroma poceni.

Kadar je smrt otroka mogoče preprečiti, je vztrajanje v zmoti pravo grozodejstvo. Naša največja zmota je, da vedno iščemo krivdo v nepredstavljivih, nepredvidljivih dejanjih posameznih storilcev nasilja, ki so izpostavljeni zaradi svoje podlosti, nemoralnosti in nestabilnosti. Dokler ljudje ne bodo spoznali, da za vsako tragedijo stoji kolektivna odgovornost, se ne bo spremenilo nič in umrlo bo še več otrok.

Zadnjih nekaj desetletij se mediji in sirřsa javnost vse bolj zavedajo različnih oblik nasilja. Kateri dejavniki so prispevali k vecji ozaveščnosti? Ali poleg »praktičnih «obstajajo kakšni pojmovni problemi, na katere moramo biti pozorni?

To, da se mediji in širša javnost vse bolj zavedajo različnih oblik nasilja, je zgolj domneva. Sam nisem tako prepričan. Naj navedem dva razloga, zaradi katerih menim, da se še vedno ne zavedamo dovolj različnih oblik nasilja, njihovega pomena in vpliva.

Prvič, gre za problem vse večje normalizacije nasilja. Skoraj nemogoče se je izogniti pogosto zelo podrobnemu, nazornemu prikazu nasilja, in to od najzgodnejših let naprej. Pri tem nosi veliko odgovornost zabavna industrija. Vzemimo, na primer, številne filme o superjunakih, ki temeljijo na stripih Marvel ali DC Comics ali celo na še vedno aktualni sagi Vojna zvezd. Ti filmi so namenjeni mlademu občinstvu in v vsakem filmu je ubitih več sto ljudi, če ne več. Ocenili so, na primer, da sta bili v filmski trilogiji Vojna zvezd ubiti več kot 2 milijardi ljudi oziroma, natančneje, več kot 2.005.645.868. To pomeni veliko nasilja. V značilnem prizoru naš junak ali superjunak ustreli ali zabode negativca, ki v trenutku pade na tla, pogosto $\mathrm{v}$ tišini in brez očitnih znakov nelagodja, in preide na uboj naslednjega negativca. Da je tako nasilje sprejemljivo za mlajše občinstvo, velja pravilo, ki v filmu ne dovoljuje prikaza krvi. Tako Britanski odbor za filmsko klasifikacijo (BBFC), neodvisni regulator, poda naslednje smernice za filme, ki so razvrščeni kot neprimerni za otroke, mlajše od I2 let: »Nasilje: v filmu je lahko prikazano zmerno nasilje, vendar brez 
podrobnosti. Poškodbe ali kri ne smejo biti izpostavljene, dovoljeni so občasni nasilni trenutki, če je to utemeljeno s kontekstom. « Takšno je stanje $\mathrm{v}$ filmski industriji, v kateri je ubijanje sto, tisoč, milijonov in milijard ljudi označeno za »zmerno nasilje«. Še več nasilja, pogosto bolj grobega in nazornega, najdemo v večmilijonski industriji računalniških iger.

Problem normalizacije nasilja ni v tem, da obstaja večja verjetnost, da ljudje zagrešijo nasilje, če so izpostavljeni vizualnemu nasilju. To morda drži, morda ne, tega še ne vemo. Tako kot v primeru pornografije empirični dokazi o omenjeni vzročni verigi še vedno niso nedvoumni. Problem leži drugje, in sicerv tem, da se nam tisto, kar je nasilno, ne zdi več nasilno. Zaradi stalne izpostavljenosti nasilju tega pojava več ne opazimo in nasilja več ne vidimo kot pretresljive resničnosti. Leta 1963 je Sheldon Wolin objavil zelo pomembno in po mojem mnenju še vedno zelo relevantno analizo nasilja. V nasprotju s tem, kar radi verjamemo, v njej trdi, da danes ni manj nasilja kot v preteklosti. Sodobna družba ni odpravila nasilja; preprosto se je naučila, kako ga prikriti. Danes nismo nujno bolj civilizirani kot naši barbarski predniki. Resnica je drugačna. Naše generacije so se nasilje naučile narediti čistejše in manj vidno. Nasilje je postalo sterilizirano, higienično, normalizirano in kot tako manj grozeče ter moralno neproblematično.

Wolin navaja primer smrtne kazni. Nimamo več javnih usmrtitev, temveč medicinske postopke za zaprtimi vrati. Brez giljotine, toda s smrtonosnim injekcijami. Rezultat je enak, vendar brez prelivanja krvi. Kot smo že rekli, so iz zabavne industrije odstranili kri, obseg nasilja pa se je povečal. Tako samo zaradi lastne zabave izpostavljeni večjemu nasilju kot kdajkoli prej, a se tega sploh ne zavedamo. Na žalost je nekaj resnice v Stalinovi srhljivi izjavi, da je smrt enega človeka tragedija, smrt milijonov pa zgolj statistika. Tudi v Hollywoodu gre vedno za velike številke: milijoni dolarjev in milijarde žrtev nasilja, zato smo izgubili sposobnost dojemanja in razumevanja resničnosti osebne tragedije.

Obstaja še en razlog, zakaj sem skeptičen do trditve, da se mnogo bolj zavedamo različnih oblik nasilja. V mislih imam pojav, ki ga Miranda Fricker v svoji knjigi Epistemic Injustice (Oxford, 2007) navaja kot hermenevtično nepravičnost. To knjigo uvrščam med najbolj izvirne, najvplivnejše in najbolj presunljive filozofske knjige, kar sem jih kdaj prebral, in jo imam za manjšo mojstrovino; zelo jo priporočam bralcem te revije. Epistemična nepravičnost je krivica, storjena nekomu, ki je v položaju poznavalca, in se kaže v obliki nezaupanja, napačne interpretacije in utišanja. Epistemična nepravičnost ima dve obliki: nepravičnost pričevanja in hermenevtično nepravičnost. Do hermenevtične nepravičnosti pride takrat, ko nekomu onemogočimo razlago doživljanja, tudi kadar je ta zelo 
osebna. Ali z drugimi besedami, hermenevtična nepravičnost se zgodi takrat, ko nekdo ni sposoben razumeti velikega dela svojega doživljanja, ker ni zmožen dostopati do skupnih virov za družbeno razlago. Pojav hermenevtične nepravičnosti nam pomaga razložiti, zakaj se nasilja ne zavedamo v tolikšni meri, kot bi se morali, ali toliko, kot bi pričakovali. Celo žrtve oziroma preživeli se morda ne zavedajo v celoti, da je tisto, čemur so bili izpostavljeni, oblika nasilja, morda zato, ker nimajo jezika, s katerim bi nasilje lahko razložili, izrazili ali sporočili. Kar razumemo pod izrazom »kultura $\ll$, je pogosto prikrita hermenevtična nepravičnost. Primerov tega je veliko, vključno s spolnim nadlegovanjem, ustrahovanjem, prevezovanjem stopal na Kitajskem itd.

Pojav radikalizacije in nasilnega ekstremizma je v ospredjepostavil težave, ki so se prej pojavljale bodisi na specializiranih tečajih o obveřčvalnih in varnostnih študijah bodisi so bile na samem robu znanstvenega zanimanja. Se vam $z d i$, da je radikalizacija problematična samo, če je povezana z nasiljem, ali obstaja kakšna druga težava, zaradi katere je vprašljiva?

Izrazu »radikalizacija « se raje izogibam, ker je svoj prvotni pomen izgubil in ga je mogoče zlahka narobe razumeti, in ker dodaja zmedo, kjer je potrebna jasnost. Zgodovinsko je bil izraz »radikalen « povezan s progresivnimi ali revolucionarnimi gibanji na levici, ki so se borila proti družbeni nepravičnosti strukturne neenakosti in grobega izkoriščanja: izhaja iz latinskega radix, kar pomeni »korenina«, radikalen pa je bil nekdo, ki je hotel spremeniti status quo $\gg$ pri korenini $\ll$.

Vendar se zdi, da se je izraz v zadnjih 200 letih spremenil in danes je izgubil prvotno ideološko identiteto. $V$ sodobnem diskurzu se $\gg$ radikalizacija « običajno uporablja za opis religioznih gibanj ali političnih skupin različnih ideoloških prepričanj, ki vključujejo politično nasilje, celo terorizem. $Z$ drugimi besedami, čeprav se je izraz »radikalizacija « prvotno uporabljal kot način opisovanja revolucionarnih idealov levice, je zdaj sinonim za terorizem. To se mi zdi najbolj osupljivo, saj sta si v svetu, kot ga vidim sam, »revolucionaren « in »terorizem « zelo različna in ju ne bi smeli zamenjevati. Zato namesto »radikalizacije« raje uporabljam izraz $\gg$ nasilni ekstremizem $\ll$.

Religiozni nasilni ekstremizem se pogosto znajde $\mathrm{v}$ novicah, domnevna grožnja verskega fundamentalizma, zlasti muslimanov, pa je ena glavnih tem pogovorov današnje mednarodne politike. Na vprašanje verskega fundamentalizma imam zelo preprost pogled: ta pojav ima $\mathrm{z}$ religijo zelo malo zveze in je povezan z desničarsko politiko. Religija je zgolj izgovor, ki ga je zrežirala manjšina, da ponovno uvede neenakosti, ki niso 
več sprejemljive, in obupan poskus izničenja družbenih in političnih koristi, doseženih v zadnjem stoletju na področju spola, rase in razreda. Kar se mene tiče, verski fundamentalizem preprosto promovira desničarsko agendo in se ne boji uporabiti nasilja za promocijo svoje vrste ekstremizma. Toda kar se je kot odziv nanj zgodilo v Evropi in ZDA, zavrača to prepričanje: desničarski verski fundamentalizem so uporabili kot veter $\mathrm{v}$ jadra konservativnih, tradicionalističnih in nacionalno-populističnih strank. Paradoks, s katerim se srečujemo danes, je brez primere, saj desničarski politiki, kot je Trump v ZDA ali kot so Orban, Le Penova in Salvini v Evropi, kar najbolje izkoristijo pogosto napihnjeno grožnjo fundamentalistične desnice, da bi okrepili svojo desničarsko agendo. Kako lahko izstopimo iz tega nesmiselnega, a nevarnega začaranega kroga? Morda potrebujemo bolj radikalno politiko, pri kateri izraz »radikalen « razumemo v njegovem prvotnem, zgodovinskem smislu.

Kateri so najbolj pereči sodobni izzivi, skaterimi se soočajo znanstveniki, ki delajo na področju vprašanj, povezanih z nasilnim ekstremizmom in političnim nasiljem na splošno?

Mislim, da je največji izziv prepričati bralce in širšo javnost, da politično nasilje ni omejeno na vojna dejanja, množična streljanja ali terorizem. S tem ne želim zanemariti vpliva ali resnosti teh ponavljajočih se dogodkov, toda po navadi monopolizirajo predstavo javnosti o nasilju, $s$ čimer tvegamo, da druge vrste nasilja ostajajo neopažene.

Kot sem že omenil, je dandanes moderna država največji povzročitelj političnega nasilja. Včasih so dejanja države tako skrajna, tako nezaslišana, da vzbudijo splošno obsojanje: kolonializem in apartheid sta očitna primera. Vendar so manj ekstremne oblike državnega nasilja lahko prav tako smrtonosne. Nasilni, neusmiljeni odzivi državnih organov na kritike njihove politike so običajna praksa v Evropi in drugje ter so vedno bolj smrtonosni od dejanj disidentov, kot na primer lahko trenutno vidimo v Hongkongu. Kljub temu je najučinkovitejši način, da država izvaja nasilje proti svojim državljanom, zakonodaja. Naj gre za novo določene drastične omejitve splava, kot v primeru Alabame in Georgie v ZDA, za naraščajoče omejitve prihoda beguncev, kot v primeru Italije, ali za neukrepanje v zvezi z izrednimi razmerami na področju okolja, je sodobna država kraj, kjer bi morali iskati primere nasilnega ekstremizma in političnega nasilja.

Vendar je nasilni ekstremizem s strani države ali drugih političnih akterjev mogoč le, če v civilni družbi obstaja tiho soglasje večine ljudi. Izziv je v tem, da ljudje spoznamo, v kolikšni meri smo vsi neposredno ali posredno odgovorni za nasilje, ki se dogaja okoli nas. Najbolj elegantno in 
prepričljivo je obstoj tega pojava mogoče dokazati v obliki nečesa, kar je Norman Geras poimenoval pogodba o medsebojni ravnodušnosti. Geras $\mathrm{v}$ istoimenski knjigi Contract of Mutual Indifference holokavst in druga velika grozodejstva našega časa razloži z ravnodušnostjo, ki jo izkazujemo ob trpljenju drugih. V Sredozemlju se je v zadnjih nekaj letih utopilo na tisoče ljudi, deloma zaradi ukrepov v nekaterih afriških državah in neukrepanja evropskih držav, pa tudi zaradi eksplicitnega oziroma implicitnega strinjanja Evropejcev, ki politikom, kot so Salvini, Farage, Le Penova in Orban, namenjajo popolno podporo.

Več vaših člankov o nasilju, na primer, Two concepts of violence in, Why is violence bad', je postalo locus classicus v filozofski literaturi o nasilju. Vas nasilje kot filozofski pojav še vedno zanima?

$S$ problematiko nasilja se ukvarjam že zadnjih I8 let, vendar imam še vedno občutek, da sem šele na začetku. Nasilje me še vedno zanima in še vedno se mi zdi, da je filozofija najboljše orodje za celovito razumevanje smisla, pomena in grozot nasilja. Od izdaje mojih knjig o nasilju sem raziskal še dve področji, ki se močno prekrivata z nasiljem - družbeno nepravičnost in kršitve človekovih pravic. Čeprav gre za različni področji $s$ svojo specializirano literaturo, se problematike družbene nepravičnosti in človekovih pravic lotevam skozi prizmo tega, kar sem se naučil iz dolgoletnega raziskovanja različnih vidikov nasilja.

Kar zadeva samo problematiko nasilja, sem se od objave svoje knjige lotil preučevanja treh specifičnih tematik. Upam, da bom svoje najnovejše eseje o nasilju nekoč v bližnji prihodnosti zbral v obliki knjige. Prva tematika je logično nadaljevanje glavne tematike moje knjige. Če sem v knjigi Violence and Social Justice trdil, da bi morali nasilje opredeliti kot kršitev integritete, me zdaj zanima, na kakšen način si lahko preživeli nasilja povrnejo integriteto oziroma celovitost. V zadnjih letih je bilo objavljenih veliko knjig o vprašanju tranzicijske pravičnosti in zlasti komisij za resnico. Čeprav obstaja nekaj pomembnih del, ki se ukvarjajo $s$ temi vprašanji, menim, da ta literatura, razen nekaj svetlih izjem, ne ponuja vedno trdne razlage pomena nasilja in izzivov, ki jih predstavlja pridobivanje znanja o nasilju. Moj prispevek, Knowing Violence: Testimony, Trust and Truth', ki je bil objavljen v reviji Revue Internationale de Philosophie (2006), predstavlja poskus raziskovanja te vrzeli. Poudarek tega članka je bil na epistemologiji nasilja in vlogi zaupanja med preživelimi nasilja, ki so doživeli kršitev svoje integritete, in tretjimi sogovorniki, ki iščejo resnico o nasilnih dogodkih. Še vedno sem osupel nad dejstvom, da delo komisij za resnico temelji na dilemi, ali lahko zaupajo pričevanjem preživelih, ko pa bi 
jih moralo bolj skrbeti, ali preživeli lahko zaupajo komisijam za resnico ali sploh še komurkoli.

Druga tematika nasilja, ki sem jo preučeval pred kratkim, obravnava nasilje nad ženskami, in sicer zlasti spolno nasilje. To je ena od najhujših stisk naše globalne skupnosti in nekaj, česar bi se morali kot človeštvo sramovati. Presenetilo me je pomanjkanje napredka, ne le, kar se tiče reševanja te težave, temveč tudi pri priznavanju, da gre za težavo. Več, ko sem prebral o spolnem nasilju, bolj mi je postajalo jasno, da sem v svoji knjigi storil osnovno napako. Vedno sem domneval, da je nasilje nekaj, kar ljudje »naredijo «, da je nasilje »dejanje «, zato moramo s pomočjo filozofije razložiti »dejanje « nasilja. Zdaj se zavedam, da je ta domneva napačna. Nasilje ni samo dejanje, ampak pojav. Razlika je komaj zaznavna, a izredno pomembna. Dejanja so opredeljena glede na kraj in čas. Dejanje ima začetek in konec. Toda pri nasilju je drugače: vedno ima začetek, vendar se za preživelega nikoli ne konča. Nasilje je časovno nedoločeno, tako da mora preživeli nasilja z nasiljem živeti še dolgo po tem, ko je dejanje že končano. To sem poskušal zajeti v naslovu članka ,The Ripples of Violence' (Feminist Review, 2016), ki sem ga napisal skupaj z Jools Gilson. Pisanje tega članka me je prisililo, da sem ponovno preučil nekatere svoje dosedanje poglede na filozofijo in nasilje. Zavedel sem se potrebe po preučevanju filozofske tradicije, ki sem jo po krivici spregledal, ko sem pisal svojo knjigo: fenomenologije. Zdaj se zavedam, kako koristna je fenomenologija za pravilno razumevanje nasilja. Pri pisanju tega članka sem tudi tvegal, kar se tiče metodologije, in sicer tako, da sem filozofska dela združil s spomini in romani. Alice Sebold, najbolj znana po romanu $V$ mojih nebesih, je pisateljica, ki jo zelo občudujem, in nekdo, ki je vedno na mojem seznamu čtiva pri predmetu o nasilju, ki ga še danes poučujem.

Zanima pa me tudi skrb vzbujajoče vprašanje, kaj storiti glede številnih dogodkov zgodovinskega nasilja. Filozofija je pomembno prispevala $\mathrm{k}$ razpravi o odpravi zgodovinske krivice, kompleksna vprašanja povrnitve škode, restitucije ali odškodnine pa niso samo teoretično zahtevna, ampak tudi politično zelo pomembna. Kolonializem je vir nesreče za človeštvo in z njegovim uničujočim vplivom se še vedno nismo spoprijeli. Kot sem že omenil, verjamem, da moramo začeti s pravilnim razumevanjem nasilja, ki ga je sprožil kolonializem, preden bomo lahko začeli pogovor o tem, kako popraviti krivico, ki jo doživljajo preživeli kolonialnega nasilja še generacije po koncu teh zgodovinskih dogodkov.

Še zadnje vprašanje: ali obstaja kakšna pomanjkljivost v analizi tako zapletenega (in protislovnega) pojava, kot je nasilje? Ali 


\section{obstajajo vprašanja, povezana $z$ nasiljem, ki so jih sodobne raz- prave zanemarile ali celo prezrle?}

Nasilje je tako razširjeno, a hkrati tudi tako zapleteno, da pri vsaki analizi tega pojava vedno obstajajo pomanjkljivosti. Ena od težav pri preučevanju nasilja je, da se večina pozornosti posveča področjem, ki so preveč raziskana, druga področja pa so skoraj v celoti zanemarjena. Ko ljudje ne vidijo dokazov o nasilju, domnevajo, da nasilja ni. To je velika napaka, v resnici je pogosto bližje resnici nasprotno: najbolj bi nas moralo skrbeti, če ni vidnih znakov nasilja, saj bi to lahko nakazovalo na njegovo popolno prevlado.

Naj navedem primer. Danes je veliko več ozaveščenosti o spolnem nasilju in spolnem nadlegovanju kot $\mathrm{v}$ preteklosti, deloma zahvaljujoč pripravljenosti tistih, ki so preživeli spolno nasilje, da se izpostavijo in pogumno delijo svoje zgodbe, kar se odraža $\mathrm{v}$ svetovnem uspehu gibanja \#MeToo. Obenem skoraj vsak pravni sistem po svetu še vedno definira posilstvo $\mathrm{v}$ smislu spolnih odnosov brez privolitve in išče dokaze o pomanjkanju soglasja pri prizadevanjih preživelih za boj ali beg. $Z$ drugimi besedami, dokazno breme je vedno na preživelem spolnega nasilja in $v$ nekaterih pravnih jurisdikcijah obtožba o posilstvu ne bo pristala na sodišču, če ni modric, ki bi pokazale, da je prišlo do fizičnega boja.

Glede tega, kako se ženske navadno odzovejo na spolni napad, v javnosti obstaja veliko napačnih domnev, ki jih povzročajo nevednost in predsodki. Domneva se, da se vedno uprejo z odločnim fizičnim in glasnim odzivom. Kadar temu ni tako, porote domnevajo, da je bilo soglasje nakazano ali da si ga napadalec lahko razumno razlaga. To je povsem napačno domnevanje. Trenutne raziskave na področju travme kažejo, da poleg boja in bega obstaja še en odziv, ki je veliko pogostejši, kot si mislimo: otrplost. Tonična nepremičnost je primarni mehanizem preživetja. Običajno se pojavi, kadar ni možnosti za boj ali beg, in oseba, ki je v nevarnosti, pade v šok. Otrplost od strahu je način, na katerega možgani preživijo veliko grožnjo. Toda $\mathrm{v}$ naši kulturi, vključno z našo pravno kulturo, ljudi obtožujemo, če se ne uprejo. Takšno temeljno nerazumevanje glede tega, kako smo programirani za odzivanje na nasilje, se odraža v zelo majhnem številu prijavljenih spolnih napadov in velikem številu tožnikov, ki se odločijo umakniti svoje dokaze in $s$ tožbo ne nadaljujejo.

Kaj se torej lahko naučimo iz tega? Prvič, da statistični podatki o nasilju ne povedo celotne zgodbe, nanje se ne moremo vedno zanesti in zlahka jih razumemo napačno. Drugič, da je treba na bolj teoretični ravni še veliko postoriti, preden bomo pravilno razumeli nasilje in družbeno nepravičnost, ki gre z nasiljem pogosto $\mathrm{z}$ roko $\mathrm{v}$ roki. 